\title{
Study on residual behaviour and flexural toughness of fibre cocktail reinforced self compacting high performance concrete after exposure to high temperature
}

\author{
Yining Ding ${ }^{\mathrm{a}, \mathrm{b}, *}$, Cecília Azevedo ${ }^{\mathrm{c}}$, J.B. Aguiar ${ }^{\mathrm{b}}$, Said Jalali ${ }^{\mathrm{b}}$ \\ a Institute of Structure Eng., Dalian University of Technology, Dalian 116023, China \\ ${ }^{\mathrm{b}} \mathrm{C}$-TAC Research Unit, Sustainable Construction Group, 4800-058 Guimaers, Portugal \\ ${ }^{\mathrm{c}}$ Centre of the Mathematics, University of Minho, Portugal
}

\section{A R T I C L E I N F O}

Article history:

Received 4 October 2008

Received in revised form 21 February 2011

Accepted 18 April 2011

Available online 2 July 2011

\section{Keywords:}

Fibre reinforced self compacting high

performance concrete (FRSCHPC)

High temperature

Residual strength

Flexural toughness

Failure pattern

\begin{abstract}
A B S T R A C T
This paper analyzed the effect of different fibres on the residual compressive strength, the ultimate load and flexural toughness, the failure pattern and the fracture energy of self compacting high performance concrete (SCHPC) after exposure to various high temperature. The micro polypropylene fibre (PP fibre) could mitigate the spalling of SCHPC member significantly, but did not show clear effect on the mechanic properties of concrete. The macro steel fibre (SF) reinforced SCHPC showed higher flexural toughness and ultimate load before and after high temperatures. The mechanical properties of hybrid fibre reinforced SCHPC (HFSCHPC) after heating were better than that of mono fibre reinforced SCHPC. The failure mode changed from pull-out of steel fibres at lower temperature to broken down of steel fibres at higher temperature. The use of hybrid fibre can be effective in providing the residual strength and failure pattern and in improving the toughness and fracture energy of SCHPC after high temperature.
\end{abstract}

\section{Introduction}

In order to achieve high flowable and self-compactable concrete, self-compacting concrete (SCC) was first developed in 1988, and SCC can be also classified into high performance concrete (HPC) due to the high workability and durability. The Increasing of the concrete strength is often one of the main desires of concrete technology and SCC with compressive strength more than $60 \mathrm{~N} / \mathrm{mm}^{2}$ has been widely used. The new term of self compacting high performance concrete (SCHPC) was introduced by Okamura et al. [1]. However, with the increasing of the compressive strength, the brittleness of concrete can be also increased. The fibres could improve the toughness and stress distribution of concrete, replace the steel reinforcement partly, reduce the crack width, enhance the bar spacing and decrease the labour costs. Therefore, a new type of SCHPC, fibre reinforced SCHPC (FRSCHPC) has been proposed by Ding et al. $[2,3]$. FRSCHPC has great potential significance for construction (e.g., for smart structures, concrete repair, bridge construction, etc.).

The workability, the strength and the toughness are the important parameters for SCHPC. The workability is a significant precondition for application of the fibre reinforced SCHPC. FRSCHPC is a special SCC and remarkably sensitive not only to the $w / b$ value and SP, but also to fibre type, fibre contents, aggregate property,

* Corresponding author. Address: State Key Laboratory of Coastal and Offshore Engineering, Dalian University of Technology, 116024 Dalian, China.

E-mail address: ynding@dlut.edu.cn (Y. Ding). etc. For the workability of SCHPC, there are some essential factors of great importance: flowability, segregation resistance, passing ability through the steel bars, levelling ability and the time-dependent behaviour [3-6].

In this work the residual behaviour means mainly the residual mechanic behaviours like the development of compressive strength, the flexural strength and the ultimate load as well as the failure pattern of SCHPC after exposure to different high temperatures. The flexural toughness and the fracture energy are discussed here specially. The addition of steel fibres may compensate the brittle property and bestow the high strength concrete with better properties including the good toughness before, during and after high exposure temperatures. The dense microstructure of HSC is also a reason of concrete degradation exposed to fire, such as spalling, which has been suggested to be due to the buildup of high internal vapour pressure in the matrix [1]. The workability and the strength, the toughness and the failure pattern, the serviceability and the durability are the significant factors for self compacting high performance concrete (SCHPC) [2].

The study of fire resistant fibre reinforced concrete (FRC) member, for instance in tunnelling under fire, include diverse issues such as the heat-transfer mechanisms and thermal properties as well as temperature field, micro structure and cracking, mechanic behaviour and theoretical models, spalling or residual strength as well as material properties at elevated temperatures. Steel fibre (SF) can be used to improve the toughness of concrete obviously and polypropylene (PP) fibre can reduce the spalling [9,10,16-22]. The 


\section{Nomenclature}

HPC high performance concrete

HSC high strength concrete

SCHPC self compacting high performance concrete

FRC fibre reinforced concrete

SCC self-compacting concrete

FRSCC fibre reinforced self-compacting concrete

FRSCHPC fibre reinforced self compacting high performance concrete

HFSCHPC hybrid fibre reinforced SCHPC

SF steel fibre

PP fibre polypropylene fibre

PP2 mixture of micro PP fibre reinforced SCHPC with fibre dosage of $2 \mathrm{~kg} / \mathrm{m}^{3}$

SF40 mixture of steel fibre reinforced SCHPC with fibre dosage of $40 \mathrm{~kg} / \mathrm{m}^{3}$

SF55 mixture of steel fibre reinforced SCHPC with fibre dosage of $55 \mathrm{~kg} / \mathrm{m}^{3}$

HF403 fibre cocktail reinforced SCHPC with $40 \mathrm{~kg} / \mathrm{m}^{3}$ macro steel fibre and $3 \mathrm{~kg} / \mathrm{m}^{3}$ micro PP fibre

HF552 fibre cocktail reinforced SCHPC with $55 \mathrm{~kg} / \mathrm{m}^{3}$ macro steel fibre and $2 \mathrm{~kg} / \mathrm{m}^{3}$ micro PP fibre
$F_{\mathrm{L}} \quad$ maximum value of the load in the interval of $0.1 \mathrm{~mm}$ $(\mathrm{kN})$

$\delta_{\mathrm{L}} \quad$ deflection corresponds to the $F_{\mathrm{L}}(\mathrm{mm})$

$F_{\mathrm{u}} \quad$ the ultimate load

$f_{\text {fct,L }} \quad$ flexural strength corresponding to $F_{\mathrm{L}}$

$D_{\mathrm{BZ}}^{b} \quad$ energy absorption of the unbroken concrete without fibre addition $(\mathrm{kN} \mathrm{mm})$

$D_{\mathrm{BZ}, 2}^{f} \quad$ energy absorption capacity ( $\mathrm{kN} \mathrm{mm}$ ) of fibre reinforced

concrete at the deflections of $\delta_{\mathrm{L}}+0.65 \mathrm{~mm}$

$D_{\mathrm{BZ}, 3}^{f} \quad$ energy absorption capacity ( $\mathrm{kN} \mathrm{mm}$ ) of fibre reinforced concrete at the deflections of $\delta_{\mathrm{L}}+2.65 \mathrm{~mm}$

$f_{\text {eq,2 }}$ equivalent flexural tensile strength (MPa) by

$\begin{array}{ll}\delta_{\mathrm{L}}+0.65 \mathrm{~mm} \\ f_{\text {eq,3 }} & \text { equivalent flexural tensile strength (MPa) by }\end{array}$

$\begin{array}{ll}G_{\mathrm{F}} & \delta_{\mathrm{L}}+2.65 \mathrm{~mm} \\ \text { fracture energy }(\mathrm{N} / \mathrm{m})\end{array}$

$l_{\mathrm{f}} \quad$ fibre length

$d_{\mathrm{f}} \quad$ the diameter of fibre combination of PP fibre and SF can be used to reduce spalling and to enhance the residual compressive strengths [3,6,15-16,19]. Numerous studies were conducted on the physical, mechanical behaviour and fire properties of concrete or FRC, and they are mainly concentrated on the compressive strength loss, spalling behaviour and the microstructure after high temperature [8-16]. However, the investigations on the ultimate load and flexural toughness, failure pattern as well as the fracture toughness of SCHPC reinforced with hybrid fibres (steel fibre + PP fibre) after the high-temperature exposures are rare, and the study on the connection among the microstructure, spalling and the flexural toughness are also restricted.

It is not intended in this study to present a complete survey of every aspect of the FRC elements. Indeed, the focus is given to study the effects of fibres on the mechanic behaviour like residual strength and ultimate load, flexural toughness and the fracture energy of SCHPC before and after the burning process, to compare the influence of different thermal properties of steel fibre and PP fibre on the SCHPC matrix and to discuss the possible connection among the microstructure, spalling and post-peak behaviour as well as the failure mode. In particular, the effects of high temperatures on the failure patterns of FRSCHPC beams in bending have been analyzed.

\section{Experiment}

\subsection{Materials}

In this program, the mix design of FRSCHPC was as follows: cement CEM I 42.5 $500 \mathrm{~kg} / \mathrm{m}^{3}$, fly ash $100 \mathrm{~kg} / \mathrm{m}^{3}$; fine aggregate $1-4 \mathrm{~mm}$, aggregate crushed limestone with particle size between 5 and $12 \mathrm{~mm}$, water/binder ratio 0.37 . The base mix design of SCHPC without fibre reinforcement is illustrated in Table 1 . The specific surface area of fly ash was $497 \mathrm{~m}^{2} / \mathrm{kg}$, and the chemical composition of fly ash is listed in Table 2. It can be seen that the main chemical components of fly ash are silicon dioxide $\left(\mathrm{SiO}_{2}\right)$ and aluminium oxide $\left(\mathrm{Al}_{2} \mathrm{O}_{3}\right)$, and they may contribute to the pozzolanic reactivity. The specific surface area of the fly ash was $475 \mathrm{~m}^{2} / \mathrm{kg}$.

Table 1

Base mixture design of SCHPC.

\begin{tabular}{clllll}
\hline Materials & $\begin{array}{l}\text { Cem I } \\
42.5 \\
\left(\mathrm{~kg} / \mathrm{m}^{3}\right)\end{array}$ & $\begin{array}{l}\text { Fly ash } \\
\left(\mathrm{kg} / \mathrm{m}^{3}\right)\end{array}$ & $\begin{array}{l}\text { Aggregate } \\
\left(\mathrm{kg} / \mathrm{m}^{3}\right)\end{array}$ & $\begin{array}{l}\mathrm{SP} \\
\left(\mathrm{kg} / \mathrm{m}^{3}\right)\end{array}$ & $\begin{array}{l}W / B \\
\text { ratio }\end{array}$ \\
\hline Content & 500 & 100 & $\begin{array}{l}0-4 \mathrm{~mm}: 764 \\
5-12 \mathrm{~mm}: 764\end{array}$ & $7.2(1.2 \%$ of binder $)$ & 0.37 \\
& & & & \\
\hline
\end{tabular}

Table 2

Chemical composition of fly ash.

\begin{tabular}{llllllll}
\hline Composition & $\mathrm{SiO}_{2}$ & $\mathrm{Al}_{2} \mathrm{O}_{3}$ & $\mathrm{CaO}$ & $\mathrm{Fe}_{2} \mathrm{O}_{3}$ & $\mathrm{~K}_{2} \mathrm{O}$ & $\mathrm{MgO}$ & $\mathrm{IL}$ \\
\hline Fly ash & 49.1 & 34.78 & 5.39 & 5.05 & 0.89 & 0.94 & 3.83 \\
\hline
\end{tabular}

Generally, the investigated fibres can be divided into micro fibres $(l 3 \mathrm{~cm})$ and macro fibres $(l \geqslant 3 \mathrm{~cm})$. The micro PP fibres are mainly used to decrease the shrinkage cracks or to restrict the initiation of the micro cracks before heating and to reduce or to prevent the spalling [2,3,8-10] at the high temperature. The macro steel fibres are used for increasing the flexural toughness and for restricting and bridging the macro cracks before heating and to enhance the residual behaviour during and after the high temperature. Different fibre types and fibre contents have been added into the mixture as follows:

- PP fibre (fibre length $l_{\mathrm{f}}=15 \mathrm{~mm}$, diameter $/ d_{\mathrm{f}}=0.03 \mathrm{~mm}$ ), density $=0.91 \mathrm{~g} / \mathrm{cm}^{3}$; tensile strength $450 \mathrm{~N} / \mathrm{mm}^{2}$; fibre content 2 and $3 \mathrm{~kg} / \mathrm{m}^{3}, 15$ millions pieces $/ \mathrm{kg}$.

- Steel fibre (fibre length $l_{\mathrm{f}}=35 \mathrm{~mm}$, diameter $/ d_{\mathrm{f}}=0.55 \mathrm{~mm}$ ), density $=7.8 \mathrm{~g} / \mathrm{cm}^{3}$; tensile strength $1200 \mathrm{~N} / \mathrm{mm}^{2}$; steel fibre content $40 \mathrm{~kg} / \mathrm{m}^{3}$ and $55 \mathrm{~kg} / \mathrm{m}^{3}, 15,000$ pieces/kg.

The various fibre contents $\left(\mathrm{kg} / \mathrm{m}^{3}\right)$, the air content and the compressive strengths of different mixtures before heating are summarized in Table 3. It can be seen that the air content of the fresh concrete increases with the increasing of fibre dosage.

The heat properties of PP fibre and steel fibre related to this article are listed in Table 4.

\subsection{Requirement and test method of the workability of fresh fibre reinforced SCHPC}

A concrete mix can only be classified as SCC if the requirements for flowability, segregation resistance, passing ability, filling ability and levelling ability are fulfiled. Based on EFNARC and other guidelines as well as the previous experimental studies

Table 3

Fibre content, air content and compressive strength.

\begin{tabular}{|c|c|c|c|c|c|c|}
\hline Mixtures & SCHPC & PP2 & SF40 & SF55 & HF403 & HF552 \\
\hline PP fibre content $\left(\mathrm{kg} / \mathrm{m}^{3}\right)$ & - & 2 & - & - & 3 & 2 \\
\hline $\begin{array}{l}\text { Volume content of PP } \\
\text { fibres (\%) }\end{array}$ & & 0.22 & & & 0.33 & 0.22 \\
\hline Steel fibre content $\left(\mathrm{kg} / \mathrm{m}^{3}\right)$ & - & - & 40 & 55 & 40 & 55 \\
\hline $\begin{array}{l}\text { Volume content of steel } \\
\text { fibres (\%) }\end{array}$ & & & 0.51 & 0.71 & 0.51 & 0.71 \\
\hline Air content $(\%)$ & $2 \%$ & $2.8 \%$ & $2.6 \%$ & $2.7 \%$ & $3.5 \%$ & $3.3 \%$ \\
\hline $\begin{array}{l}\text { Compressive strength } \\
\text { (28 days) (MPa) }\end{array}$ & 64 & 60 & 64 & 65 & 63 & 65 \\
\hline
\end{tabular}


Table 4

Thermal properties of steel and PP fibres.

\begin{tabular}{lll}
\hline Thermal properties & PP fibre & Steel fibre \\
\hline Melting point $\left({ }^{\circ} \mathrm{C}\right)$ & $160-180$ & $1410-1540$ \\
Heat transfer coefficient & $0.1-0.22 \mathrm{~W} /\left(\mathrm{m}^{\circ} \mathrm{C}\right)$ & $43 \mathrm{~W} / \mathrm{m}{ }^{\circ} \mathrm{C}\left(\lambda_{\mathrm{SF}}\right)$ \\
& $\left(\lambda_{\mathrm{PP}}\right)$ & \\
Thermal expansion & $13 \times 10^{-6} \mathrm{~m} / \mathrm{m}^{\circ} \mathrm{C}$ & $\begin{array}{l}1 \times 10^{-4}-7 \times 10^{-3} \mathrm{~m} / \mathrm{m}^{\circ} \mathrm{C} \\
\left(\alpha_{\mathrm{SF}}\right)\end{array}$ \\
$\begin{array}{c}\text { coefficient } \\
\left(\alpha_{\mathrm{PP}}\right)\end{array}$ &
\end{tabular}

[2-8,16], the test methods used in this research work were a slump flow test (for assessing the flowability), J-Ring test (for assessing the passing ability and flowability as well segregation resistance) and a U-tube test (for assessing passing ability, flowability and levelling ability). For the slump flow test, the requirements are somewhat different [2-8], generally the acceptance criteria of slump flow spread regarding the workability is from the minimum value of $55 \mathrm{~cm}$ up to a maximum value of $85 \mathrm{~cm}$. From experiences, it is known that the slump flow spread of SCHPC should be not less than $(\geqslant) 60 \mathrm{~cm}$ [4]. The difference of the mixtures inside and outside the J-Ring $\left(L_{\mathrm{J}}\right)$ and the slump flow spread of J-Ring $\left(J_{\mathrm{sf}}\right)$ have to be measured. The conditions for a successful FRSCHPC are as follows: $J_{\mathrm{sf}} \geqslant 55 \mathrm{~cm}$ and $L_{\mathrm{J}} \leqslant 2 \mathrm{~cm}$. The workability criteria for the fresh SCC using U-tube is to measure the height of the concrete in the compartment that has been filled, in two places and calculate the mean $\left(h_{1}\right)$. Measure also the height in the other compartment $\left(h_{2}\right)$. Calculate the filling height $h_{1}-h_{2}$. The near the filling height $h_{1}-h_{2}$ is to zero, the better the flow and passing ability of the fresh concrete. The maximum allowable value of filling height is that $h_{1}-h_{2} \leqslant 3 \mathrm{~cm}[4-8]$.

Fig. 1 shows details of these tests on SCHPC with $40 \mathrm{~kg} / \mathrm{m}^{3} \mathrm{SF}$. It can be seen that the workability of the FRSCHPC used fulfils the requirements of SCC. The average results of mixtures for different fibre types and fibre contents are shown in Table 5.

\subsection{Hardened specimens and experiment}

The specimens were cast without vibration. Twenty-four specimens for each mixture, including 12 cubes $(100 \times 100 \times 100 \mathrm{~mm})$ and 12 beams ( $100 \times$ $100 \times 400 \mathrm{~mm}$ ), were cast in steel moulds. After casting, all the moulded specimens were covered with plastic sheets and water saturated burlap, and left in the casting room. The specimens were than demoulded $24 \mathrm{~h}$ after casting of the concrete. Afterwards they were transferred to the moist curing room and stored at $20^{\circ} \mathrm{C} \pm 2{ }^{\circ} \mathrm{C}$ and relative humidity $(\mathrm{RH}) \geqslant 95 \%$ until preparation for testing.

The mix design shall satisfy all performance for the concrete both in fresh and hardened states. In order to investigate the compressive strength of FRC, uniaxial compression test was carried out on cubic specimens, measuring $150 \times$ $150 \times 150 \mathrm{~mm}$, with a constant loading rate of $0.6 \mathrm{Mpa} / \mathrm{s}$, after the curing phase according to Chinese guidelines [11,12].

At the unheated temperature of $20^{\circ} \mathrm{C}, \mathrm{SCHPC}$ without fibre and with mono fibre reinforcement were adopted as the reference samples. Three of the cubes and three of the beams of each mixture were tested at the room temperature. The remaining nine cubes and nine beams were subjected to three different temperatures in an electrical furnace: three cubes and three beams subjected at $300{ }^{\circ} \mathrm{C}$, three cubes and three beams subjected at $600{ }^{\circ} \mathrm{C}$ and three cubes and three beams subjected at $900{ }^{\circ} \mathrm{C}$ for $3 \mathrm{~h}$ (see Fig. 2).

Although the influence factors on fire or high temperature condition have been debated for long time, they can generally be considered to include the effect of temperature-time process or temperature difference. The temperature-time relationship is the precondition for analyzing the heating effect and can significantly influence the deformation of concrete constituents or members under high temperature [19,30-32]. In the furnace, all the specimens are heated at an increasing rate of $6{ }^{\circ} \mathrm{C} / \mathrm{min}$ and the peak temperatures are maintained for $3 \mathrm{~h}$ (Fig. 2). After heating, the specimens are cooled down to the room temperature, the tests of the residual compressive strength, the flexural toughness and the fracture energy as well as the failure pattern are carried out.

The SCHPC beams reinforced with different fibres have been tested to investigate the flexural behaviour $[10,16,19,27,31,33]$, including the load-deflection behaviours and load-crack mouth opening displacement (CMOD) relations. The tests regarding the fibre influence on the post-crack behaviour before and after
Table 5

Test results of workability.

\begin{tabular}{lllllll}
\hline Mixtures & SCHPC & PP2 & SF40 & SF55 & HF403 & HF552 \\
\hline PP fibre content $\left(\mathrm{kg} / \mathrm{m}^{3}\right)$ & - & 2 & - & - & 3 & 2 \\
Steel fibre content $\left(\mathrm{kg} / \mathrm{m}^{3}\right)$ & - & - & 40 & 55 & 40 & 55 \\
Slump flow $(\mathrm{mm})$ & 678 & 632 & 662 & 646 & 604 & 608 \\
J-Ring, $J_{\text {sf }}(\mathrm{mm})$ & 650 & 585 & 610 & 590 & 545 & 540 \\
J-Ring, $L_{\mathrm{J}}(\mathrm{mm})$ & 5 & 20 & 10 & 15 & 35 & 30 \\
U-box $\left(h_{1}-h_{2}, \mathrm{~mm}\right)$ & 5 & 25 & 23 & 27 & 32 & 30 \\
\hline
\end{tabular}

burning process have been carried out. The beam size is $B$ (width) $\times H$ (depth) $\times L$ (length) $=100 \mathrm{~mm} \times 100 \mathrm{~mm} \times 400 \mathrm{~mm}$, tested on a span of $300 \mathrm{~mm}$ (Fig. 3). All the beams are notched at midspan. The width and depth of the notch are $3 \mathrm{~mm}$ and $15 \mathrm{~mm}$, respectively. The flexural test is determined by the deformation-controlled experiment. A close loop test machine is used and the deflection is measured using two LVDTs, the deformation rate of the midspan is $0.2 \mathrm{~mm} / \mathrm{min}$. The loaddeflection curves are used to evaluate the flexural strength and flexural toughness of FRSCHPC

After burning, some PP fibre reinforced SCHPC specimens have been selected and divided into two parts for SEM analyzing as illustrated in Fig. 4. The cross section of specimen is about $4 \mathrm{~cm} \times 4 \mathrm{~cm}$, and the thickness of specimen was about $2 \mathrm{~cm}$, the two sides of the surface or the two parts of all specimens have been investigated carefully, no PP fibres exist in the concrete matrix because they melt already after high temperature. The type of the microscope used was JSM-5310 LV, Scanning Microscope.

\section{Results and analysis}

\subsection{Workability}

Fibre reinforced SCHPC (FRSCHPC) is a special SCC and remarkably sensitive to the fibre type and fibre contents. Developing FRSCHPC requires careful control of factors to ensure the high performance of concrete such as high flowability and high strength, high toughness and improved failure patterns. For conventional fibre reinforced concrete (FRC), the maximum fibre contents and fibre types are usually determined by the toughness or mechanic property required. However, the fibre contents and fibre types of FRSCHPC are mainly determined by the high flowability and segregation resistance of fresh mixtures $[3,7,8,16]$.

The experimental results of FRSCHPC workability (the slump flow test, the J-Ring test and the U-tube test) are summarized in Table 5. It can be seen that:

All values of the slump flow spread are larger than $60 \mathrm{~cm}$.

Most values regarding J-Ring test meet the requirements of SCC, except for the values of $J_{s f}$ for HF552 and HF40, which are lightly lower than $55 \mathrm{~cm}$

- Most values regarding J-Ring test meet the requirements of SCC, except for the values of $L_{\mathrm{J}}$ for HF552 and HF403, which are lightly higher than $2 \mathrm{~cm}$.

- Most values regarding U-tube test meet the workability requirement, except for the values of $h_{1}-h_{2}$ for HF552 and HF403, which are close to $3 \mathrm{~cm}$ or lightly higher than $3 \mathrm{~cm}$.

The mixtures of SCHPC, PP2, SF40 and SF55 indicate well flowability and no segregation and fulfil the requirement for SCHPC
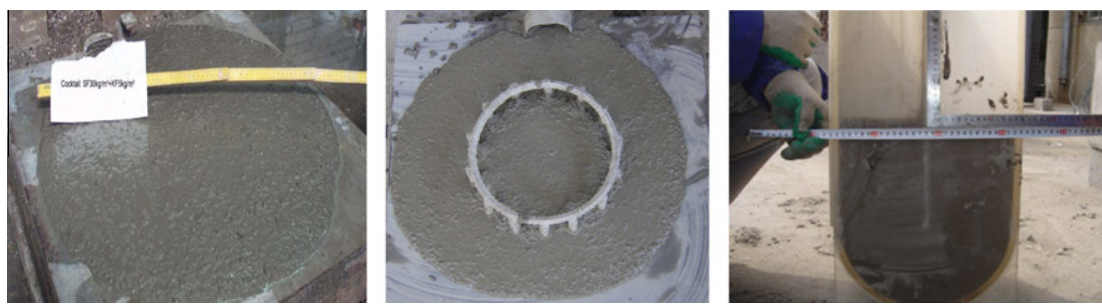

Fig. 1. Tests of workability of SCC with $40 \mathrm{~kg} / \mathrm{m}^{3}$ steel fibre. 


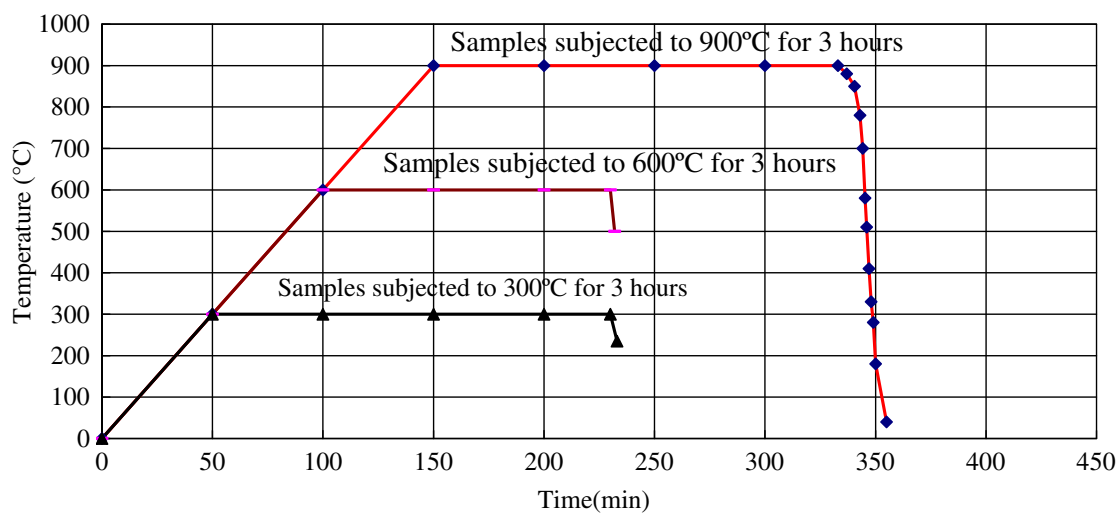

Fig. 2. Temperature-time relation.

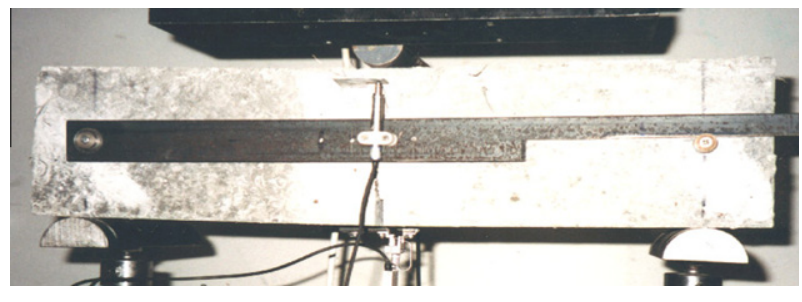

Fig. 3. Set-up for flexural testing.

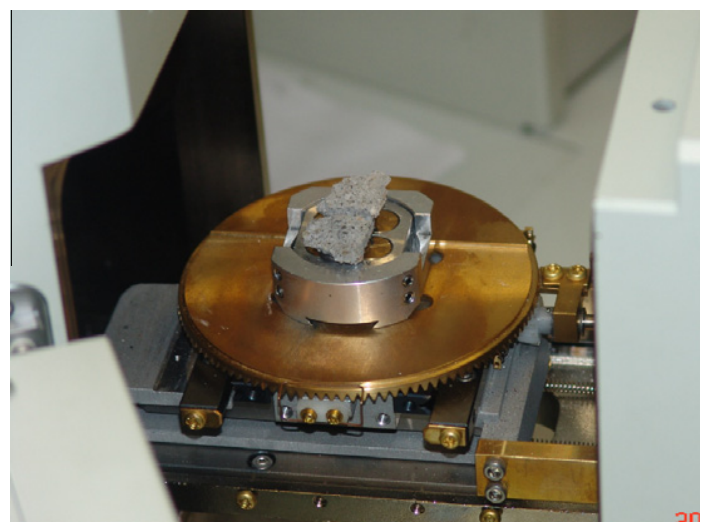

Fig. 4. Specimen in the SEM equipment.

[4-8,16]. The experiments show that the hybrid combinations of $55 \mathrm{~kg} / \mathrm{m}^{3}$ steel fibres and $2 \mathrm{~kg} / \mathrm{m}^{3}$ PP fibres (HF552) as well as $40 \mathrm{~kg} / \mathrm{m}^{3}$ steel fibres and $3 \mathrm{~kg} / \mathrm{m}^{3}$ PP fibres (HF403) could be the upper boundary of the fibre content regarding the workability required by SCHPC.

\subsection{Residual compressive strength of hardened concrete samples}

The mean values of compressive strength of all samples after 28 days are illustrated in Table 3 . It can be seen that the addition of fibres has no significant influence on the compressive strength. The compressive strength of all the samples exceeded $60 \mathrm{~N} / \mathrm{mm}^{2}$ after 28 days. Therefore, the proposed mix design has produced the concrete that meets satisfactorily the strength requirement of fibre reinforced HPC $[3,16]$. It can be seen that the PP fibres show lightly negative influence on the compressive strength for SCHPC before heating. The addition of steel fibres aids in converting the

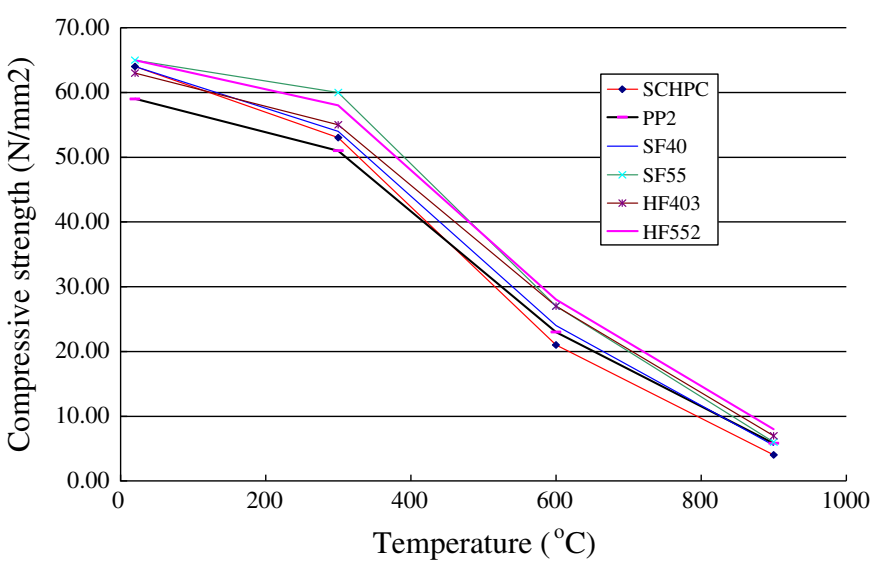

Fig. 5. Comparison of compressive strength after various temperatures.

brittle properties of concrete into a ductile material, but no significant trend of improving compressive strength was observed.

In order to analyze the loss of compressive strength after heating, two concepts of "relative residual compressive strength $f_{\mathrm{cu}, \mathrm{T}} / f_{\mathrm{cu}}$ " $[2,10,16-19]$ and "relative loss in compressive strength $\left[\left(f_{\mathrm{cu}}-f_{\mathrm{cu}, \mathrm{T}}\right) / f_{\mathrm{cu}}\right]$ " were introduced, where $f_{\mathrm{cu}, \mathrm{T}}$ is the compressive strength measured after different high temperatures, and $f_{\text {cu }}$ is the compressive strength measured before heating. Fig. 5 shows the comparison of compression tests of all mixtures with different fibres before and after exposure to various high temperatures. Table 6 illustrates the relative loss in compressive strength of SCHPC and FRSCHPC with different fibre types and fibre contents. The various high temperatures induce the loss of compressive strength as expected.

For SCHPC without fibre, it showed the greatest loss in strength. For the exposure temperatures of $300{ }^{\circ} \mathrm{C}, 600{ }^{\circ} \mathrm{C}$ and $900{ }^{\circ} \mathrm{C}$, the relative loss in compressive strengths were $17 \%, 67 \%$ and $94 \%$ compared to the original strength before heating, respectively. In

Table 6

Relative loss in compressive strength of SCHPC and FRSCHPC (\%).

\begin{tabular}{lllll}
\hline$\left(f_{\mathrm{cu}}-f_{\mathrm{cu}, \mathrm{T}}\right) / f_{\mathrm{cu}}(\%)$ & $20{ }^{\circ} \mathrm{C}(\%)$ & $300{ }^{\circ} \mathrm{C}(\%)$ & $600{ }^{\circ} \mathrm{C}(\%)$ & $900{ }^{\circ} \mathrm{C}(\%)$ \\
\hline SCHPC & 1 & 17 & 67 & 94 \\
PP2 & 1 & 14 & 60 & 89 \\
SF40 & 1 & 16 & 63 & 91 \\
SF55 & 1 & 8 & 59 & 91 \\
HF403 & 1 & 13 & 57 & 89 \\
HF552 & 1 & 11 & 57 & 88 \\
\hline
\end{tabular}


connection with Fig. 5, it can be seen that relative to the strength prior to the exposure to the high temperature, there is a continuously strength loss of all mixtures with an increase in temperature. The investigation of Neville with different heating rate and mix design showed that the relative residual strength of concrete was about $40 \%$ at $600{ }^{\circ} \mathrm{C}$ [15]. The high loss in compressive strength and explosive spalling for normal SCHPC without fibres can be partly due to the low permeability and dense microstructure, which restricts the releasing of vapour pressure from the pore and leads to buildup of high internal pressure during heating.

For FRSCHPC with PP fibre, the relative loss in strength (14\%) was lower than that of SCHPC without fibres (17\%) after exposure to high temperature of $300^{\circ} \mathrm{C}$. As shown in Fig. 5, when the maximum exposure temperature achieved $900^{\circ} \mathrm{C}$, the relative residual compressive strength was $11 \%$ of the original strength for PP 2 and the relative loss in strength was $89 \%$. In some studies $[9,10,19$ 21,30 ], PP fibre shows beneficial effect on the residual strength of concrete after the high-temperature exposures. On of the important reasons is that PP fibres melt and vapourize due to the lower melting point $\left(160-180^{\circ} \mathrm{C}\right)$ during the rapid temperature increasing process, which makes free space in the micro-channels in the concrete matrix (see Fig. 6), decreasing tension stress in the capillary that reduces the compression stress in the concrete matrix.

At the high temperature, SF can mitigate expansion of concrete due to the rapid temperature change and reduce the large temperature gradient due to the higher heat transfer coefficient of SF, and restrict the development of crack in SCHPC [10,17-19,31]. When the temperature reached to $300^{\circ} \mathrm{C}, 600^{\circ} \mathrm{C}$ and $900^{\circ} \mathrm{C}$, the relative loss on compressive strength of SF 40 were about $16 \%, 63 \%$ and $91 \%$, and the relative residual compressive strengths of SF40 were $84 \%, 37 \%$ and $9 \%$ of the original value before heating. The relative loss on compressive strength of SF55 were about 8\%, 59\% and $91 \%$, and the relative residual compressive strengths of SF55 were $92 \%, 41 \%$ and $9 \%[10,19]$. It means that the FRSCHPC with higher steel fibre content has smaller loss in compressive strength and higher residual compressive strength than that with lower one.

Under the heating process of this work, for maximum exposure temperature below $300{ }^{\circ} \mathrm{C}$, the loss in compressive strength was relatively small, more than $83 \%$ of the original compressive strength of all the mixtures can be maintained after heating. If maximum exposure temperature increases to $600^{\circ} \mathrm{C}$, SCHPC without fibre suffer a greater compressive strength loss than fibre reinforced SCHPC (FRSCHPC), the residual compressive strengths of all hybrid fibre reinforced SCHPC samples (HF403 and HF552) and SF55 were still over $27 \mathrm{~N} / \mathrm{mm}^{2}$, it is about $43 \%$ of the original strength of unheated samples. At maximum exposure temperatures of $900^{\circ} \mathrm{C}$, the strengths of all mixtures reached the minimum values; the SCHPC samples without fibres kept only $6 \%$ of the original unheated compressive strength; however, the relative residual compressive

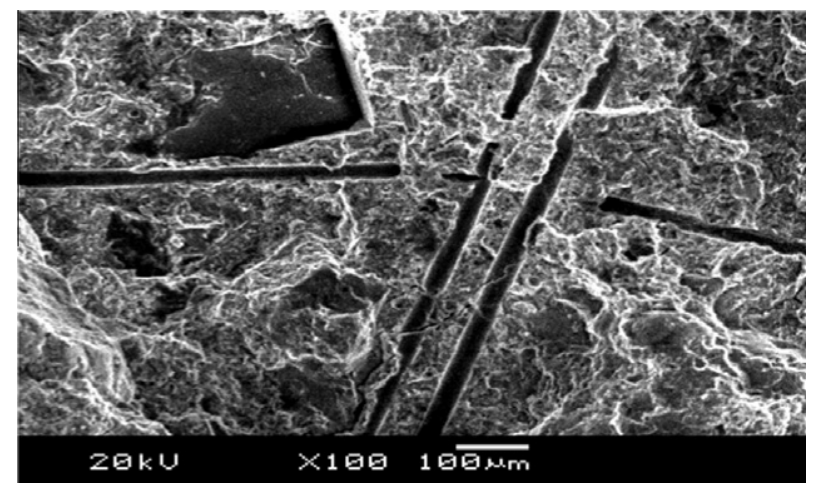

Fig. 6. Micro channels due to melting of PP fibres. strengths of all hybrid fibre reinforced SCHPC samples (HF403 and HF552) retained more than $11 \%$ of the original strength of unheated samples due to the positive composite effect of steel fibres and PP fibres. The fibre cocktail reinforced samples of HF552 show the smallest compressive strength loss after $3 \mathrm{~h}$ heating at $900{ }^{\circ} \mathrm{C}$.

\subsection{Flexural behaviour and fracture energy}

The flexural strength and ultimate load after cracking, flexural toughness and fracture energy of SCHPC and FRSCHPC with various fibres before and after exposure to different temperatures are analyzed. The factors of flexural behaviour $f_{\mathrm{fct}, \mathrm{L}}, D_{\mathrm{BZ}, 2}^{f}, f_{\mathrm{eq}, 2}, D_{\mathrm{BZ}, 3}^{f}$ and $f_{\text {eq, } 3}$ are calculated based on RILEM TC 162-TDF [27]. The fracture energy $G_{f}$ is evaluated on the basis of RILEM Recommendation TC50-FCM [33]. Where: $F_{\mathrm{L}}(\mathrm{kN})$ is the maximum load in the interval of $0.1 \mathrm{~mm} ; F_{\mathrm{u}}$ is the ultimate load; $f_{\mathrm{fct}, \mathrm{L}}$ is the flexural strength corresponding to $F_{\mathrm{L}} ; \delta_{\mathrm{L}}$ is the deflection corresponds to the $F_{\mathrm{L}}(\mathrm{mm})$; $D_{\mathrm{BZ}}^{b}$ is the energy absorption of the unbroken concrete without fibre $(\mathrm{kNmm}) ; D_{\mathrm{BZ}, 2}^{f}$ and $D_{\mathrm{BZ}, 3}^{f}$ are the energy absorption of fibre reinforced concrete at the deflections of $\left(\delta_{\mathrm{L}}+0.65 \mathrm{~mm}\right)$ and $\left(\delta_{\mathrm{L}}+\right.$ $2.65 \mathrm{~mm}$ ), respectively; $f_{\mathrm{eq}, 2}$ and $f_{\mathrm{eq}, 3}$ are the equivalent flexural strengths by the deflections of $\left(\delta_{\mathrm{L}}+0.65 \mathrm{~mm}\right)$ and $\left(\delta_{\mathrm{L}}+2.65 \mathrm{~mm}\right)$, respectively.

Figs. 7-9 show the load-deflection curves of different mixtures with or without fibre reinforcement in three-point bending test at room temperature of $20^{\circ} \mathrm{C}$ and after exposure to high temperatures of $300{ }^{\circ} \mathrm{C}, 600{ }^{\circ} \mathrm{C}$ and $900{ }^{\circ} \mathrm{C}$. The calculated results of the flexural strength $\left(f_{\mathrm{fct}, 1}\right)$ and ultimate load $\left(F_{\mathrm{u}}\right)$, the energy absorption $\left(D_{\mathrm{BZ}, 2}^{f}\right.$ and $\left.D_{\mathrm{BZ}, 3}^{f}\right)$ and equivalent flexural strength $\left(f_{\mathrm{eq}, 2}\right.$ and $\left.f_{\text {eq,3 }}\right)$ as well as fracture energy $\left(G_{\mathrm{f}}\right)$ are summarized in Table 7 , where the values are averages of three specimens. It can be seen that the ultimate load $\left(F_{\mathrm{u}}\right)$ after cracking of SCHPC without fibres drops faster than that of FRSCHPC. The FRSCHPC can absorb much more energy over the entire deflection zone than that of SCHPC without fibres. For steel fibre reinforced SCHPC, both the ductility and the fracture energy of beams become stronger with the increasing of steel fibre content. FRSCHPC with hybrid fibres exhibits superior flexural toughness and fracture energy compared to the mono fibre reinforced SCHPC beams.

For the flexural behaviour at the room temperature before heating in Fig. 7, SCHPC with $2 \mathrm{~kg} / \mathrm{m}^{3}$ PP fibres indicates the similar flexural behaviour as SCHPC (see Fig. 7) without fibres, but great improvement of $G_{f}$ is noticed, for normal SCHPC without fibres $G_{\mathrm{f}}=236 \mathrm{~N} / \mathrm{m}$ and for PP2 $G_{\mathrm{f}}=1222$, an increment of about $418 \%$. For SCHPC and PP2, the cracking load $F_{\mathrm{L}}$ was equal to the ultimate load $F_{\mathrm{U}}$. After cracking, the load bearing capacities of SCHPC and PP2 drop abruptly. However, this brittle property is changed by adding $40 \mathrm{~kg} / \mathrm{m}^{3}$ steel fibres (SF40). For SF40, the cracking load $F_{\mathrm{L}}$ was

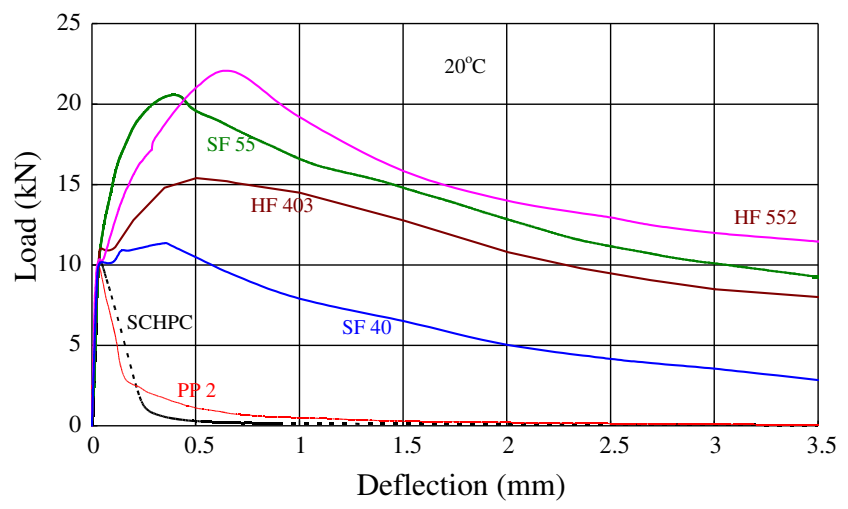

Fig. 7. Comparison of load-deflection curves of FRHPC with different fibres before heating. 


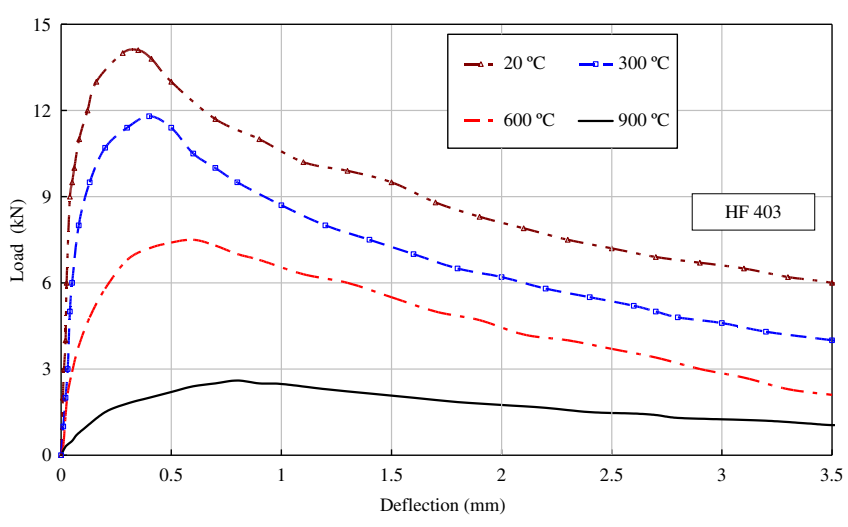

Fig. 8. Comparison of load-deflection curves of hybrid fibre reinforced samples HF403 under different temperatures.

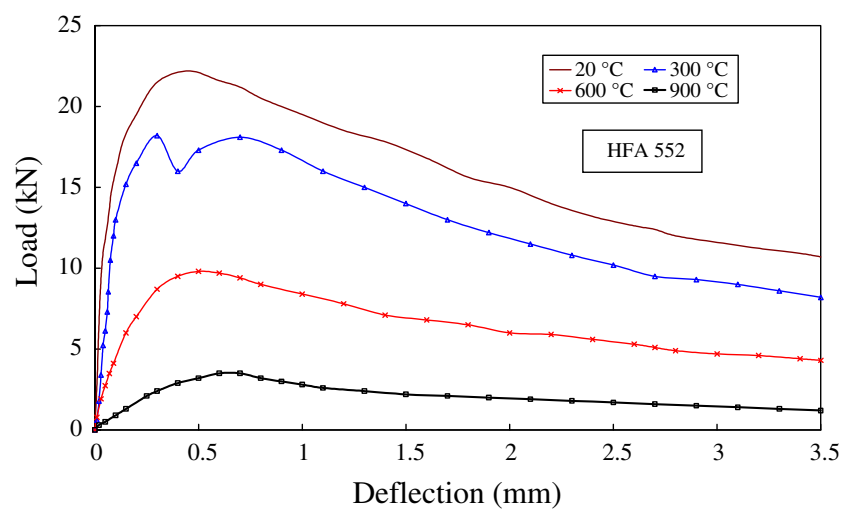

Fig. 9. Comparison of load-deflection curves of hybrid fibre reinforced samples HFA552 under different temperatures.

$10.15 \mathrm{kN}$ at the deflection of $0.04 \mathrm{~mm}$ corresponding to the first crack, and the ultimate load $F_{\mathrm{U}}=11.3 \mathrm{kN}$ at the deflection of $0.3 \mathrm{~mm}$, indicating an increment of $11 \%$. The fibre cocktail reinforced beams (HF403) showed much higher values of flexural toughness, fracture energy and ultimate load after cracking. Compared to the $F_{\mathrm{L}}$ at the deflection of $0.05 \mathrm{~mm}$, the ultimate load $F_{\mathrm{U}}(=14.1 \mathrm{kN})$ at the deflection of $0.35 \mathrm{~mm}$ of HF403 increased about $48 \%$. HF552 showed the highest ultimate load bearing capacity after cracking of all sechs different SCHPC mixtures.

After heating at different high temperatures, the flexural strength and the ultimate load, flexural toughness and fracture energy of all mixes drop clearly with the increasing of the temperatures, and the load bearing capacity decreases monotonic with the increasing of the deflection. From Table 7, it can be seen that $f_{\mathrm{fct}, \mathrm{L}}, F_{\mathrm{U}},\left(D_{\mathrm{BZ}, 2}^{f}, f_{\mathrm{eq}, 2},\left(D_{\mathrm{BZ}, 3}^{f}\right.\right.$ and $f_{\mathrm{eq}, 3}$ as well as $G_{\mathrm{f}}$ decrease with the increasing of temperature. Compared to $G_{\mathrm{f}}$ of SCHPC without fibres, the increment for $G_{f}$ of PP2 achieved about $380 \%$ after $3 \mathrm{~h}$ heating at $300{ }^{\circ} \mathrm{C}$, and achieved about $460 \%$ after $600{ }^{\circ} \mathrm{C}$. All the mechanic values including $G_{\mathrm{f}}$ decreased clearly with the increasing of temperature and were very low due mainly to serious damage on the concrete matrix after heating at $900{ }^{\circ} \mathrm{C}$. However, the values of toughness parameters and fracture energy with hybrid fibres are higher than that with mono fibre reinforced SCHPC. For instance, after the maximum exposure temperature at $900{ }^{\circ} \mathrm{C}$, the values of $\mathrm{HF} 403\left(f_{\text {eq, } 3}=1.26 \mathrm{~N} / \mathrm{mm}^{2}, G_{\mathrm{f}}=1029\right.$ $\mathrm{N} / \mathrm{m})$ are close to the values of SF55 $\left(f_{\text {eq }, 3}=1.36 \mathrm{~N} / \mathrm{mm}^{2}\right.$, $\left.G_{\mathrm{f}}=1139 \mathrm{~N} / \mathrm{m}\right)$ and much higher that those of SF40 $\left(f_{\text {eq. } 3}=0.8\right.$ $\mathrm{N} / \mathrm{mm}^{2}, G_{\mathrm{f}}=682 \mathrm{~N} / \mathrm{m}$ ). Compared to SF40, the equivalent flexural strength $f_{\text {eq, } 3}$ and the fracture energy $G_{\mathrm{f}}$ of HF403 increased by $57.5 \%$ and $50.9 \%$, although the total fibre dosage gained only $7.5 \%$. This indicates that the addition of $3 \mathrm{~kg} / \mathrm{m}^{3}$ PP fibre had an approximately equivalent effect to that of increasing SF dosage from 40 to $55 \mathrm{~kg} / \mathrm{m}^{3}$, and a clear composite effect of two different fibre types can be achieved.

\subsection{Failure pattern of FRSCHPC}

It is interesting to note that PP fibres can mitigate the spalling of SCHPC beams and steel fibre can enhance the residual load bearing capacity and the toughness as well as fracture energy of concrete at high temperatures, and that can be the precondition for using fibre cocktail in SCHPC as fire resistant materials.

Table 7

Flexural strength, ultimate load, parameters of flexural toughness and fracture energy of different mixes subjected to various burning temperatures.

\begin{tabular}{|c|c|c|c|c|c|c|c|c|c|c|}
\hline Specimens & & $F_{\mathrm{L}}(\mathrm{kN})$ & $f_{\mathrm{fct}, \mathrm{L}}(\mathrm{MPa})$ & $F_{\mathrm{u}}(\mathrm{kN})$ & $D_{\mathrm{BZ}}^{b}(\mathrm{~N} \mathrm{~mm})$ & $D_{\mathrm{BZ}, 2}^{f}(\mathrm{~N} \mathrm{~mm})$ & $f_{\mathrm{eq}, 2}(\mathrm{MPa})$ & $D_{\mathrm{BZ}, 3}^{f}(\mathrm{~N} \mathrm{~mm})$ & $f_{\text {eq, } 3}(\mathrm{MPa})$ & $G_{\mathrm{f}}(\mathrm{N} / \mathrm{m})$ \\
\hline \multirow[t]{6}{*}{$20^{\circ} \mathrm{C}$} & SCHPC & 10.2 & 2.53 & 10.2 & 1680 & - & - & - & - & 236 \\
\hline & PP2 & 10.2 & 2.44 & 10.6 & 1685 & 1832 & 0.09 & 2462 & 0.08 & 1222 \\
\hline & SF40 & 10.15 & 2.51 & 11.3 & 1781 & 7166 & 6.7 & 19,402 & 4.39 & 3874 \\
\hline & SF55 & 11.9 & 2.93 & 20.6 & 2077 & 12,566 & 13.1 & 40,723 & 9.63 & 12,704 \\
\hline & HF403 & 9.50 & 2.35 & 14.1 & 1663 & 8657 & 8.71 & 26,577 & 6.21 & 6072 \\
\hline & HF552 & 11.79 & 2.91 & 22.2 & 2063 & 13,616 & 14.39 & 46,359 & 11.04 & 17,461 \\
\hline \multirow[t]{6}{*}{$300^{\circ} \mathrm{C}$} & SCHPC & 8.50 & 2.1 & 8.5 & 1368 & 1368 & - & 1368 & - & 180 \\
\hline & PP2 & 9.82 & 2.42 & 9.82 & 1811 & 2390 & 0.29 & 2585 & 0.08 & 866 \\
\hline & SF40 & 8.75 & 2.16 & 9.51 & 1531 & 5997 & 5.56 & 16,692 & 3.78 & 3001 \\
\hline & SF55 & 6.13 & 1.51 & 16.5 & 1072 & 9796 & 10.87 & 35,275 & 8.52 & 9478 \\
\hline & HF403 & 6.0 & 1.48 & 11.8 & 1050 & 7040 & 7.46 & 21,035 & 4.98 & 4147 \\
\hline & HF552 & 6.18 & 1.52 & 18.1 & 1081 & 10,784 & 12.09 & 37,544 & 9.08 & 10,497 \\
\hline \multirow[t]{6}{*}{$600^{\circ} \mathrm{C}$} & SCHPC & 2.20 & 0.54 & 3.14 & 385 & 385 & - & 385 & - & 89 \\
\hline & PP2 & 2.61 & 0.64 & 3.9 & 451 & 1652 & 0.59 & 2591 & 0.21 & 504 \\
\hline & SF40 & 2.73 & 0.67 & 5.5 & 477 & 3223 & 3.42 & 9418 & 2.23 & 1518 \\
\hline & SF55 & 2.67 & 0.66 & 8.4 & 467 & 4676 & 5.24 & 16,866 & 4.09 & 3624 \\
\hline & HF403 & 2.9 & 0.72 & 7.5 & 508 & 4310 & 4.74 & 14,615 & 3.51 & 2482 \\
\hline & HF552 & 2.73 & 0.67 & 9.8 & 478 & 5434 & 6.17 & 19,124 & 4.65 & 4676 \\
\hline \multirow[t]{6}{*}{$900{ }^{\circ} \mathrm{C}$} & SCHPC & 0.16 & 0.04 & 0.38 & 28 & 28 & - & 28 & - & 39 \\
\hline & PP2 & 0.23 & 0.05 & 0.48 & 35 & 284 & 0.12 & 575 & 0.05 & 35 \\
\hline & SF40 & 0.30 & 0.07 & 1.66 & 53 & 867 & 1.01 & 3251 & 0.80 & 682 \\
\hline & SF55 & 0.40 & 0.1 & 3.20 & 70 & 1456 & 1.73 & 5521 & 1.36 & 1134 \\
\hline & HF403 & 0.50 & 0.12 & 2.60 & 88 & 1211 & 1.4 & 5146 & 1.26 & 1029 \\
\hline & HF552 & 0.50 & 0.12 & 3.50 & 88 & 1643 & 1.94 & 6088 & 1.49 & 1420 \\
\hline
\end{tabular}




\subsubsection{Steel fibre reinforced matrix}

Fig. 10 illustrates the strong spalling of SCHPC beam without fibres. It can be seen that the spalling of high performance concrete beam without fibres is very strong after $600{ }^{\circ} \mathrm{C}$. Fig. 11 demonstrates the spalling of FRSCHPC beam with $40 \mathrm{~kg} / \mathrm{m}^{3}$ steel fibres after the maximum exposure temperature at $600{ }^{\circ} \mathrm{C}$. In comparison with Fig. 10, it can be seen that the damage and spalling of SCHPC beam can be declined by using of steel fibres. At the high temperature, SF can mitigate expansion of concrete due to the rapid temperature change and reduce the large temperature gradient due to the higher heat transfer coefficient, and restrict the development of crack in SCHPC and bridging the thermal cracks [10,17-19,31]. Fig. 12 shows the scanning electron microscope (SEM) analysis of fracture surface of matrix with steel fibre of the same FRSCHPC beam after $3 \mathrm{~h}$ heating at $600{ }^{\circ} \mathrm{C}$. The image of SEM picture (see Fig. 12) indicates that some micro cracks have been formed. Lightly spalling can be one of the reasons, and non-uniform deformation among the paste, aggregate and steel fibres [15,30,34-37] during heating process and the reversal process of cooling down can be another reason.

Figs. 13a and $b$ illustrate the failure patterns of beam sections of steel fibre reinforced SCHPC with fibre content of $55 \mathrm{~kg} / \mathrm{m}^{3}$ (SF55). If the maximum exposure temperature does not exceed $600{ }^{\circ} \mathrm{C}$, the steel fibres are mainly pulled out from the matrix [10,19,31], and the failure mode of FRSCHPC beams was somehow ductile. After maximum exposure temperature of $900{ }^{\circ} \mathrm{C}$, the steel fibres become

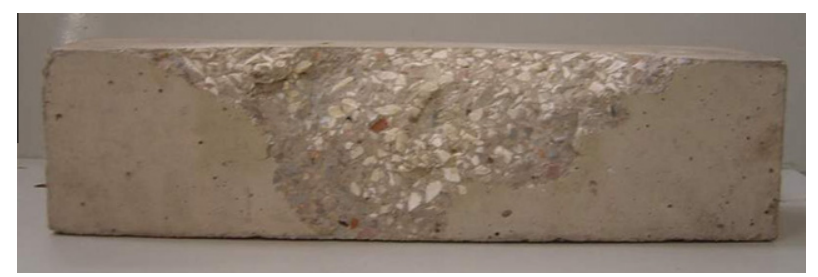

Fig. 10. Spalling of SCHPC beams without fibres after $600{ }^{\circ} \mathrm{C}$.

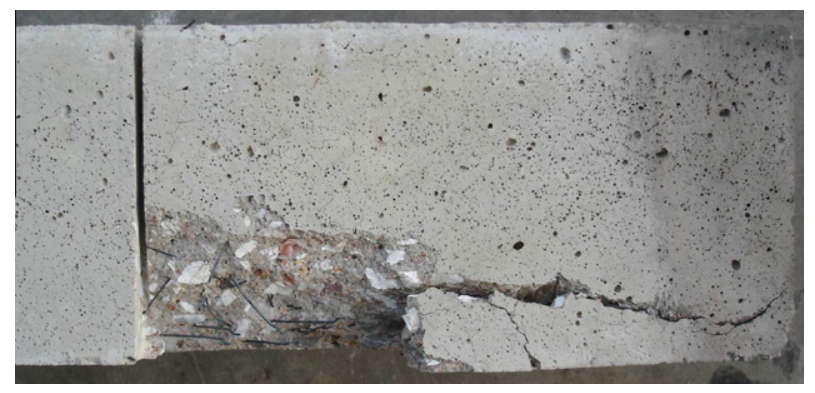

Fig. 11. Spalling of SF40 after $600^{\circ} \mathrm{C}$.

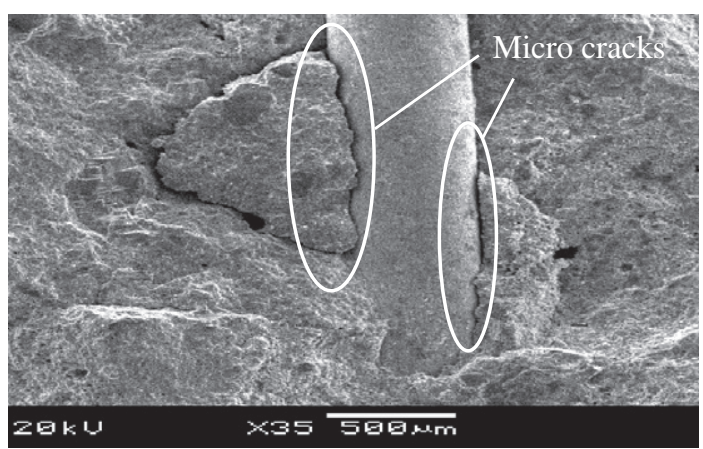

Fig. 12. Steel fibre in the matrix after $600{ }^{\circ} \mathrm{C}$

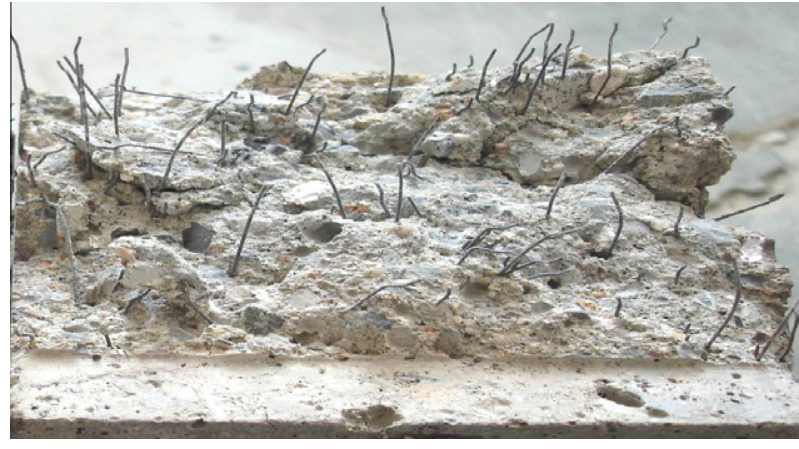

Fig. 13a. Failure pattern of SF55 after $600{ }^{\circ} \mathrm{C}$.

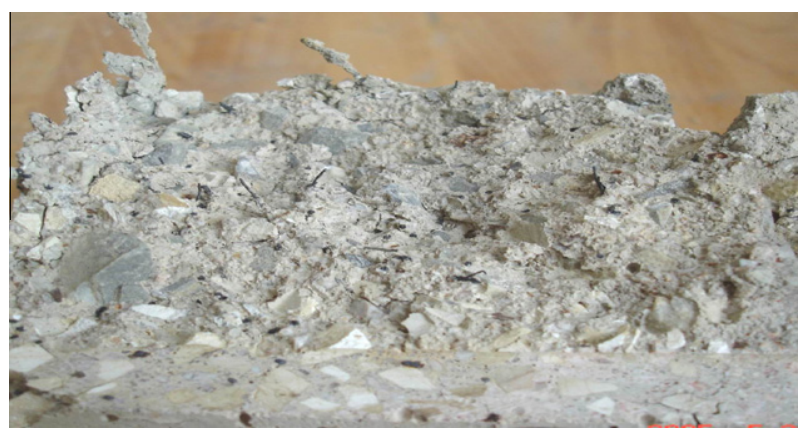

Fig. 13b. Failure pattern of SF55 after $900{ }^{\circ} \mathrm{C}$.

fragile and mechanic behaviour of SF is strongly damaged, both fibres and bending beams are broken down abruptly and indicate strong brittle failure.

Based on the results in Table 7 and in combination with Figs. $10-13$, it can be seen that with the increasing of heating temperature, the mechanical property and toughness of SCHPC beam with the same fibre type and fibre content are degraded and declined clearly (Figs. 13a and b). Both the concrete matrix and the steel fibres are damaged strongly after $900{ }^{\circ} \mathrm{C}$. After $600^{\circ} \mathrm{C}$ the well distributed steel fibres in the matrix acting as a three dimensional net $[2,3,10,13-19,31,36]$ can still transfer the tensile force in some extent. Therefore, the flexural toughness factors or post-crack behaviour (calculated by factors like $\left(D_{\mathrm{BZ}, 2}^{f}, f_{\mathrm{eq}, 2},\left(D_{\mathrm{BZ}, 3}^{f}\right.\right.$ and $\left.f_{\mathrm{eq}, 3}\right)$ of steel fibre reinforced SCHPC beams show a great improvement compared to those of SCHPC without fibres or only with PP fibres (see Table 7).

\subsubsection{PP fibre reinforced matrix}

Fig. 14 demonstrates the SCHPC beam with $2 \mathrm{~kg} / \mathrm{m}^{3}$ PP fibre (PP2) after the maximum exposure temperature at $600{ }^{\circ} \mathrm{C}$. Fig. 6 shows the SEM analysis of PP2 matrix after $3 \mathrm{~h}$ heating at $600{ }^{\circ} \mathrm{C}$ and reveals why the spalling is mitigated during and after high temperature. The traces caused by melted PP fibres in the SCHPC matrix can be observed clearly, which can provide the micro-channels to release the water vapour pressure in the matrix pores for mitigating the explosive spalling (Fig. 6). Therefore, there is no visible spalling on the surface of PP2 beam (Fig. 14); even so, the post-crack behaviour of mono PP fibre reinforced beam after high temperatures are much lower than that of SF40.

\subsubsection{Fibre cocktail reinforced matrix}

Fig. 15 demonstrates SEM analysis of fracture surface for the distribution of macro steel fibre and micro PP fibres in the HF552 matrix after the bending test at room temperature. The failure pattern of steel fibre is mainly pulled out from the matrix (Fig. 16b), PP 


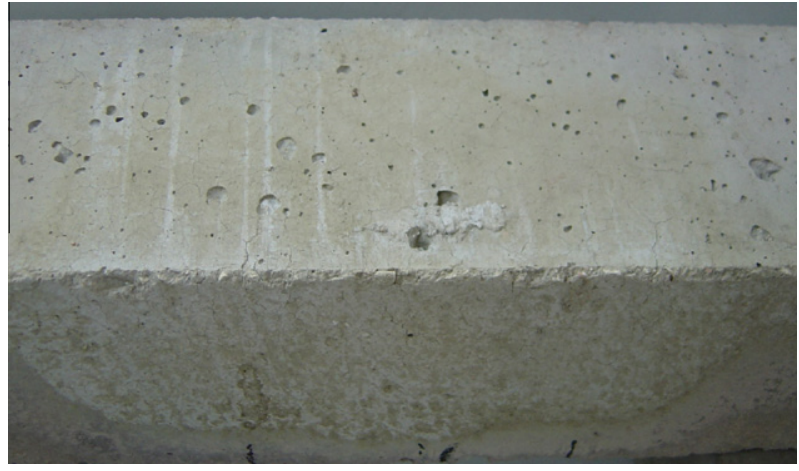

Fig. 14. No spalling of beam PP2 after $600^{\circ} \mathrm{C}$.

fibres are partly pulled out and partly broken down (Fig. 16a). Fig. 17 shows the fibre cocktail reinforced SCHPC beam (HF552) after $3 \mathrm{~h}$ heating at the maximum exposure temperature of $900{ }^{\circ} \mathrm{C}$. Similar to Fig. 14 , there is no visible spalling on SCHPC beam with $55 \mathrm{~kg} / \mathrm{m}^{3}$ steel fibres and $2 \mathrm{~kg} / \mathrm{m}^{3}$ PP fibres. In addition, HF552 and HF443 show excellent flexural behaviour and fracture energy before and after the heating treatment at various high temperatures (see Table 7).

\subsection{Discussion}

Depending on the different high temperatures, the heat transfer coefficient of steel fibre $\lambda_{\mathrm{SF}}$ varies between 28 and $50 \mathrm{~W} / \mathrm{m}{ }^{\circ} \mathrm{C}$, and the heat transfer coefficient of concrete $\lambda_{C}$ varies between 1.1 and

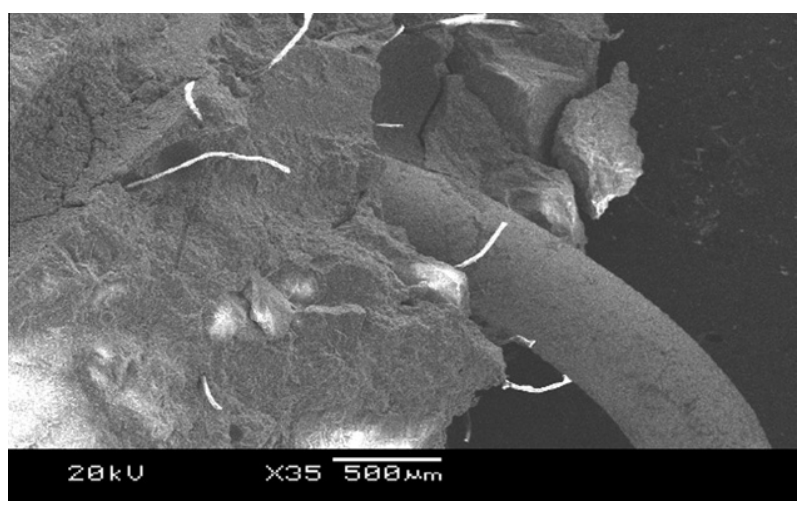

Fig. 15. Different fibres in the matrix of HF552 before heating.

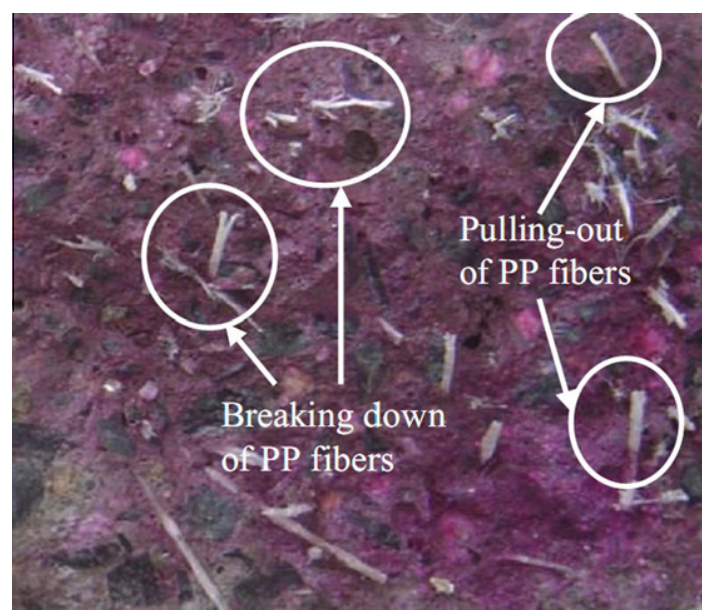

Fig. 16a. Pulling out and breaking down of PP fibres before heating

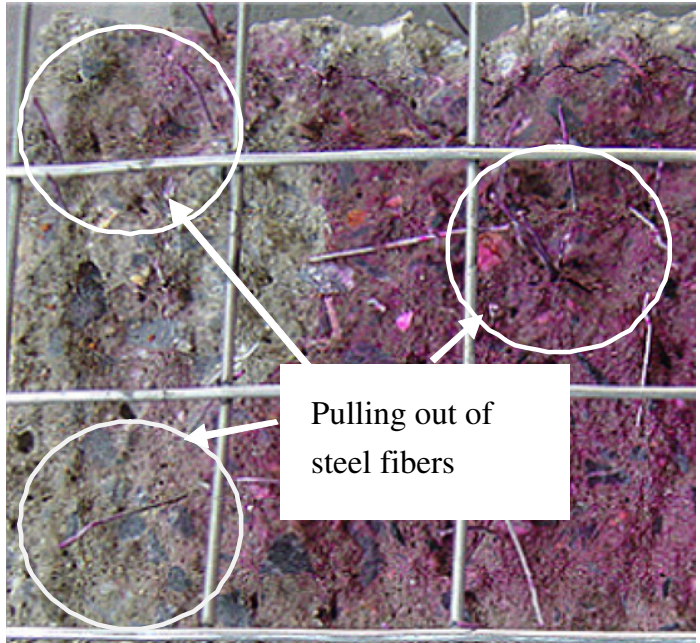

Fig. 16b. Pulling out of steel fibres.

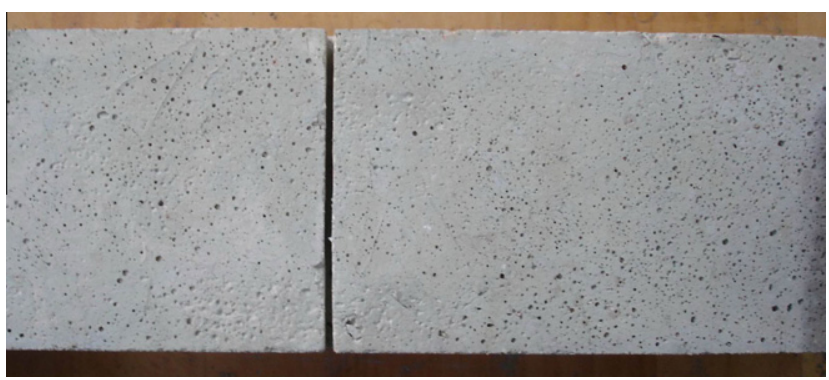

Fig. 17. No spalling of beam HF552 after $900{ }^{\circ} \mathrm{C}$.

$1.3 \mathrm{~W} / \mathrm{m}^{\circ} \mathrm{C}, \lambda_{\mathrm{SF}}$ is almost 20 to 50 times higher than $\lambda_{\mathrm{C}}$; the thermal expansion properties $(\alpha)$ between concrete and steel fibre are also different, the thermal expansion coefficient of SF $\alpha_{\mathrm{SF}}$ varies between $1 \times 10^{-4}$ and $7 \times 10^{-3} 1 /{ }^{\circ} \mathrm{C}$, and the thermal expansion coefficient of concrete $\alpha_{\mathrm{C}}$ varies between $6 \times 10^{-6}$ and $1 \times 10^{-2} 1 /{ }^{\circ} \mathrm{C}$ $[31,34]$. The different thermal expansion coefficient of steel fibre and concrete can induce the different thermal strains between steel fibre and concrete during and after the heating process. It can be assumed that the thermal expansion of steel fibre is mainly along the fibre length $[31,34,35]$. But, the thermal expansion of concrete matrix should be considered in a three dimensional thermal field. For fibre reinforced concrete under heating, the thermal strains may occur transverse or parallel to the fibre axis (Fig. 18):

1) The strains transverse to the fibre are one of the concerns which may influence the bond behaviour negatively between fibre and concrete matrix.

2) The another concern is the thermal expansion parallel to the fibre axis. For the thermal expansion component of concrete parallel to the fibre axis, there are also two major effect parameters:

a) different thermal expansion coefficients may cause various thermal strains between steel fibre and concrete during and after the heating process;

b) the steel fibre is oxidized and the mechanic property is damaged. For the fibre-concrete interface, the bond effect between fibre and concrete matrix is therefore declined strongly.

These two effect parameters may affect the bond behaviour between fibre and concrete matrix very negatively. 


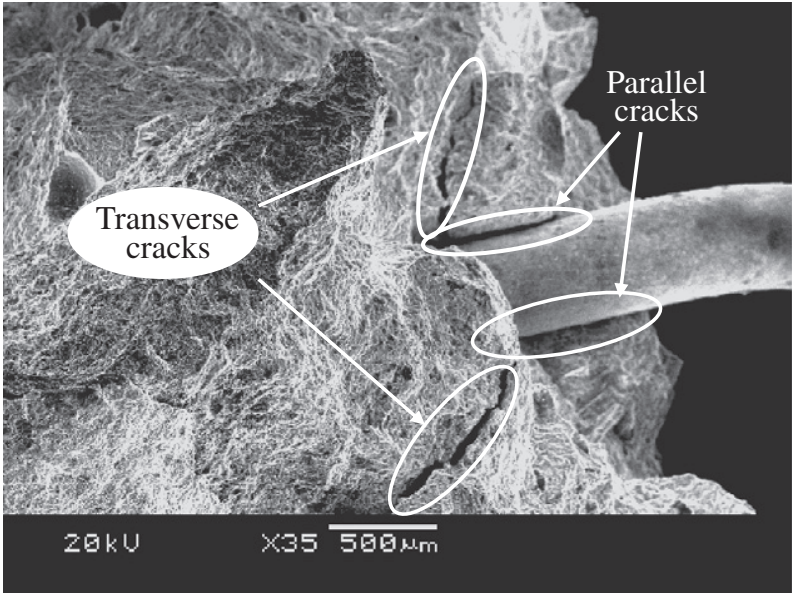

Fig. 18. Thermal cracks between matrix and steel fibre after exposure to $900{ }^{\circ} \mathrm{C}$.

From discussed above, it can be seen that the bond behaviour between steel fibre and matrix can be influenced negatively by both the different thermal expansion coefficient of steel fibre and concrete as well as the oxidized steel fibres during and after the heating process $[10,28-30,34-37]$. The high heat transfer coefficient $\lambda_{\mathrm{SF}}$ of steel fibre can positive affect the temperature field and reduce the thermal stress of the FRSCHPC. That positive effect will increase with the increasing of steel fibre content.

During the heating process, initial cracks form when the maximum tensile strain of concrete is exceeded at the weak points, which are distributed randomly. The micro cracks among paste, aggregate and steel fibres can be induced both by the high temperature and by non-uniform deformation during heating process and the reversal process of cooling down. Similar to steel rebar in the concrete, concrete and fibre have the same deformation and thus the same strain $\varepsilon$ before cracking: $\varepsilon_{\mathrm{SF}}=\varepsilon_{\mathrm{C}}=\varepsilon$. Due to the formation of cracks, the compatibility of deformations between fibre and concrete can be damaged by the different thermal expansion during the burning and cooling down process and this compatibility is not maintained. The thermal crack may form transverse or parallel to the fibre axis [34-37] (see Fig. 18). Thermal cracks parallel to the axis of fibre can be called as splitting or slipped cracks caused by the radial component of the bond stresses leading to splitting or spalling of the concrete (see Figs. 18-20).

Based on the experimental results in Table 7, the load-deflection curves from Figs. 7-9 and the pictures of Figs. 10-17 as well as Refs. [7-10,14-30], some preliminary assumptions can be verified:

1) There are clear composite effects of steel fibre and PP fibre on SCHPC. In this work, the composite effect has two different functions:

- The first function relates to the composite effect of hybrid fibres (SF + PP) on SCHPC member at the room temperature before heating. In this stage, the micro PP fibres are used to reduce the plastic cracks as well as the micro cracks, and the macro structure steel fibres are used to enhance the ductility and to reduce the structure cracks. The combination of using micro PP fibre and macro steel fibre in the concrete matrix increases the post-peak behaviour and provides an uniformly stress redistribution, decrease both the micro cracks and the structure macro cracks which can improve the serviceability and durability of the concrete member.

- The second function relates to the composite effect of hybrid fibres on SCHPC member at high temperature. During the heating process, PP fibres can mitigate the

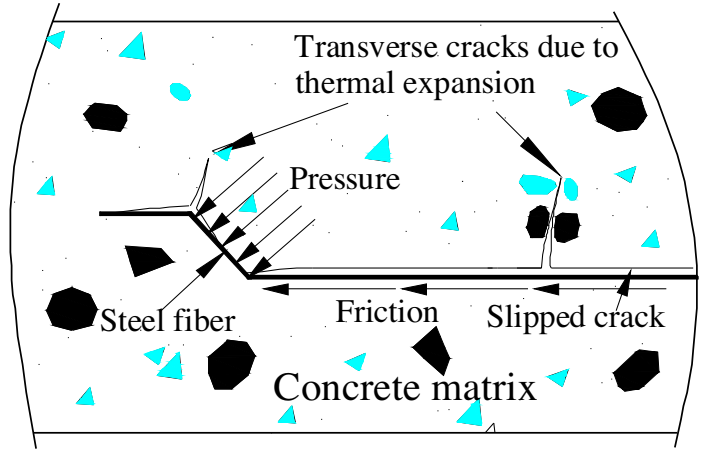

Fig. 19. Thermal cracks between matrix and steel fibre during heating process.

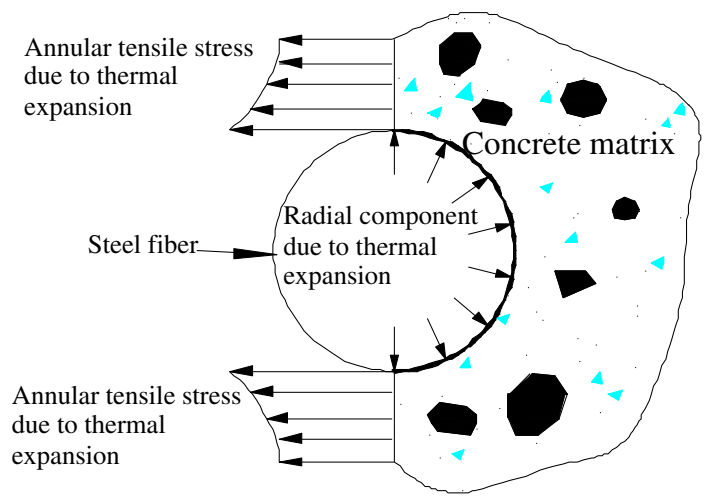

Fig. 20. Thermal stress around steel fibre and matrix during heating process.

vapour pressure and prevent the explosive spalling, enhance the residual compressive strength and the fracture energy after high temperature. The thermal behaviour of steel fibres can affect the temperature field and reduce the thermal stress of matrix. Steel fibres enhance the ultimate load bearing capacity after cracking, increase the flexural toughness and the fracture energy during and after heating, but cannot reduce the spalling. The composite effect of fibre cocktail demonstrates excellent residual mechanic behaviour and spalling resistance, improving failure pattern and retaining member integrity after exposure to high temperature.

2) The heat transfer coefficient of steel fibre is much larger than that of concrete over the entire heating process. The three dimensional distributed steel fibres in the concrete matrix may provide a more evenly distributed temperature field, decrease the temperature gradient and therefore mitigate the thermal stress as well as the damage on the micro structure. This is one of the reasons that steel fibres can increase the residual strength, the ultimate load and the toughness as well as the fracture energy after heating.

Since the micro PP fibre contribution is mainly activated at high temperatures, and the macro steel fibre contribution is mainly activated for large beam deflection and wide crack before, during and after various high temperatures [7-10,16-20,28-31], the significant improvement of the residual mechanic properties as well as the spalling resistant of fibre cocktail reinforced SCHPC over a large deflection zone can be achieved.

\subsection{Economic evaluation}

The above mentioned investigations showed the good technological properties of fibre reinforced SCHPC. However, for a possible 
Table 8

Cost comparison of SCC with and without fibres.

\begin{tabular}{lc}
\hline Materials & Cost $\left(\right.$ Euro $\left./ \mathrm{m}^{3}\right)$ \\
\hline SCHPC without fibres & 80 \\
SCHPC with steel mesh & 190 \\
PP2 & 86.67 \\
SF40 & 150 \\
SF55 & 176.67 \\
HF403 & 162.2 \\
HF552 & 184.4 \\
\hline
\end{tabular}

practical using of various fibres, the cost benefit is an important precondition. Table 8 illustrates the cost comparison of SCC without fibres, with steel mesh and with different fibres.

From Table 8, it can be seen that: compared with the plain concrete of SCHPC, the material cost increases with the fibre dosage. But, our major purposes and industrial background are using hybrid fibres to enhance the residual mechanical behaviour and to replace the conventional steel mesh of RC member in underground construction after exposure to fire accident. The often-used reinforcement ratio of tunnel element is between $1 \%$ and $1.4 \%$, and the cost is also listed in Table 8. Because the conventional RC member is not capable to show any load bearing ability during and after the fire if the spalling of concrete cover occurs and then the steel rebar deforms strongly and the bond between concrete matrix and rebar is destroyed. Therefore, we focus on the toughness of fibre cocktail reinforced SCHPC under high temperature. Considering the load bearing capacity of SCHPC with steel mesh at room temperature of $20^{\circ} \mathrm{C}[14,34-37]$, the steel reinforcement can be replaced by the combination of $55 \mathrm{~kg} / \mathrm{m}^{3} \mathrm{SF}$ and $2 \mathrm{~kg} / \mathrm{m}^{3}$ PP fibre, and the material cost is similar.

For RC member without steel mesh or only with very low steel ratio, however, besides the material cost, we should consider other factors as follows:

- There is a valuable foreground for structural using of fibre cocktail due to the good toughness before heating, and the strong improved residual mechanical behaviour and spalling resistance as well as the ductility after heating.

- We also should consider the cost benefit of the short construction period by replacing conventional steel mesh, because macro fibres can be advantageous for the partial or total replacement of stirrups $[7,8,10,14,19,31]$. Using FRSCHPC can significantly reduce the construction period and costs, the binding of reinforcement, and it can be easily placed in thin or irregularly shaped sections where the arrangement of stirrups may be difficult.

- The steel fibres can improve the concrete quality and the postcrack performance and reduce the brittle behaviour of normal concrete and high strength concrete. The fibres into the concrete enhance the mechanical behaviour of RC members and it leads to a change in failure mode from a brittle failure into a ductile failure, the fibres also tend to reduce crack width and spacing, which can improve the serviceability and the durability of concrete structure.

FRSCHPC combines the advantages of both SCC and FRC. However, research work on the study of FRSCC beams, especially dealing with the residual mechanical behaviour of SFSCC after high temperature, is still very limited.

\section{Conclusions}

The influences of various fibres on the residual compressive strength and flexural strength, ultimate load and flexural toughness, fracture energy and failure pattern of FRSCHPC before and after the high-temperature exposures have been investigated. The investigations show that the fibre cocktail reinforced SCHPC exhibit strong toughness, a clear enhanced mechanical property compared to other HPC materials, in addition to a much improved member integrity after high temperature. The following conclusions can be drawn from the results:

- The combination of steel fibres and PP fibres shows positive composite effect on the post-peak behaviour of SCHPC materials before and after exposure to high temperature.

- During the high temperature, PP fibre can mitigate or prevent the explosive spalling, enhance the residual strength and fracture energy, but does not increase the toughness of SCHPC.

- Steel fibre can improve the residual compressive strength, enhance the ductility of SCHPC subjected to different high temperatures, but it is not able to mitigate the spalling of concrete at high temperature. This observation supports the use of fibre cocktail in SCHPC as fire resistant materials.

- After exposure to high temperature, the flexural behaviour and the fracture energy of all samples decrease, and the higher the maximum exposure temperature, the lower the toughness parameters and fracture energy like $D_{\mathrm{BZ}, 2}^{f}, D_{\mathrm{BZ}, 3}^{f}, f_{\mathrm{eq}, 2}$ and $f_{\mathrm{eq}, 3}$ and $G_{f}$ of FRSCHPC, they are very sensitive to the fibre content and fibre types.

- For maximum exposure temperature of $900{ }^{\circ} \mathrm{C}$, the failure model of steel fibre changes from pull-out at lower temperature to tensile failure (broken down). The failure pattern of FRSCHPC beam changes from ductile pattern into brittle one.

- In addition to a much improved failure pattern and member integrity after high temperature, the fibre cocktail reinforced SCHPC exhibit superior flexural toughness, higher ultimate load and fracture energy compared to the mono fibre reinforced SCHPC after high temperature.

This conclusion suggests that the use of fibre cocktail reinforced SCHPC material can be very effective in reducing thermal stress and in improving composite effect of hybrid fibres on the postcrack behaviours during heating process at high temperature.

\section{Acknowledgements}

The authors acknowledge the National Natural Science Foundation of China (Grant: 50278013) and Fundação para a Ciência e a Tecnologia (FCT) (SFRH/BPD/22680/2005). The authors also acknowledge the assistance of former Ph.D. students Dr. Dong X. and Dr. Wang Y.

\section{References}

[1] Okamura H, Ouchi M. Self-compacting high performance concrete. Prog Struct Mat Eng 1998;1(4):378-83.

[2] Ding Y, Zhang Y, Thomas A. The investigation on strength and flexural toughness of fibre cocktail reinforced self-compacting high performance concrete. Constr Build Mater 2009;23(1):448-52.

[3] Ding Y, Liu S, Zhang Y, Thomas A. The investigation on the workability of fibre cocktail reinforced self-compacting high performance concrete. Constr Build Mater 2008;22(7):1462-70.

[4] EFNARC: specification and guidelines for self compacting concrete; February 2002.

[5] The European guidelines for self compacting concrete, specification, production and use; May 2005.

[6] Brite EuRam. Task 9 end product-SCC guidelines; 2000

[7] Ding Y, You Zh, Jalali S. Composite effect of steel fibres and stirrups on shear behaviour of Beams using self-consolidating concrete. Eng Struct 2011;33: 107-17.

[8] Ding Y, Liu H, Togal F, Jalali S. Hybrid fiber influence on strength and toughness of RC beams. Compos Struct 2010;92:2083-9.

[9] Kalifa P, Menneteau F, Quenard D. Spalling and pore pressure in HPC at high temperatures. Cem Concr Res 2000;30(12):1915-27. 
[10] Dong X. Research on mechanical properties and spalling behaviours of FRHPC subjected to high temperature and fire. Ph.D. dissertation, Dalian University of Technology; 2006 [in Chinese].

[11] China Standardization Association of Engineering Construction Standard CECS 13-1989. Testing methods of fiber reinforced concrete; 1989.

[12] Specification for design and construction of steel fiber reinforced concrete structures. CECS 38: 92. Testing methods of fiber reinforced concrete; 1989.

[13] Ding Y, Kusterle W. Compressive stress-strain-relationship of steel fibre reinforced concrete at early age. Cem Concr Res 2000;30(10):1573-9.

[14] Ding Y, Kusterle W. Comparative study between steel fibre reinforced concrete and steel mesh reinforced concrete at early ages in the panel tests. Cem Concr Res 1999;29:1827-34.

[15] Neville AM. Properties of concrete. Longman Group Limited; 1995. p. 384-86. ISBN:0-582-23070-5.

[16] Ding Y. Eigenschaften von faserbeton und faserspritzbeton. Hannover, Germany: Ibidem-Verlag; November 2003. ISBN:3-89821-295-5.

[17] Lau A, Anson M. Effect of high temperatures on high performance steel fibre reinforced concrete. Cem Concr Res 2006;36(9):1698-707.

[18] Giaccio M, Zerbino L. Mechanical behaviour of thermally damaged highstrength steel fibre reinforced concrete. Mater Struct 2005;38:335-42.

[19] Dong X, Ding Y. Mechanical properties of SFHPC after high temperatures. J Southwest Jiaotong Univ (English edition) 2007;15(1):12-9.

[20] Kalifa P, Chéné G, Gallé Ch. High-temperature behaviour of HPC with polypropylene fibres from spalling to microstructure. Cem Concr Res 2001;31(10):1487-99.

[21] Hertz D. Limits of spalling of fire-exposed concrete. Fire Saf J 2003;38(2): 103-16.

[22] Chan Yn, Luo X, Sun W. Compressive strength and pore structure of highperformance concrete after exposure to high temperature up to $800{ }^{\circ} \mathrm{C}$. Cem Concr Res 2000;30(2):247-51.

[23] Zollo RF. Fiber-reinforced concrete: an overview after $30 \mathrm{y}$ of development. Cem Concr Compos 1997;19(2):107-22.

[24] Xiao J, Koenig G. Study on concrete at high temperature in China - an overview. Fire Saf J 2004;39:89-103.
[25] Wu B, Su X, Li H, Yuan J. Effect of high temperature on residual mechanical properties of confined and unconfined high-strength concrete. ACI Mater J 2002;99(4):399-407.

[26] Zhang B, Bicanic N, Pearce Cj, Phillips DV. Relationship between brittleness and moisture loss of concrete exposed to high temperatures. Cem Concr Res 2002;32(3):363-71.

[27] Rilem Tc. 162-TDF: test and design methods for steel fiber reinforced concrete-bending test. Mater Struct 2002;35:579-82.

[28] Chen B, Liu JY. Residual strength of hybrid-fiber-reinforced high-strength concrete after exposure to high temperatures. Cem Concr Res 2004;30(6): 1065-9.

[29] Kodur R, Sultan A. Effect of temperature on thermal properties of highstrength concrete. J Mater Civil Eng ASCE 2003;15(2):101-7.

[30] Ding Y, Wang Y, Zhang Y, Paulini P. Investigation of the stress and strain state of clay pipes under fire condition. Ceram Int 2009;35(1):63-7.

[31] Wang Y. Study on high temperature behaviours of FRHPC pipe members. Ph.D. dissertation, Dalian University of Technology; 2008 [in Chinese].

[32] Chiaia B, Fantilli Ap, Vallini P. Evaluation of minimum reinforcement ratio in FRC members and application to tunnel linings. Mater Struct 2007;40(6): 593-604.

[33] RILEM draft recommendation TC50-FCM: determination of fracture energy of mortar and concrete by means of three point bend tests on notched beams. Mater Struct 1985;18(106):285-90.

[34] Guo ZH. Mechanic behaviour of concrete materials and elements under normal and high temperature. Tsinhua University, 2006-6-1. ISBN:730212109 [in Chinese]

[35] Kordina K, Meyer-Ottens C. Beton brandschutz handbuch. Betom Verlag; 1981. ISBN:3-7640-0136-4.

[36] Ding Y. Investigations into the relationship between deflection and crack mouth opening displacement of SFRC beam. Constr Build Mater 2011;25: 2432-40. doi:10.1016/j.conbuildmat. 2010. 11.05.

[37] Structure concrete. In: Textbook on behaviour, design and performance, vol. 1. Updated knowledge of the CEB/FIP model code 1990; July 1999. 